\title{
Enhanced oxidation power in photoelectrocatalysis based on a micrometer-localized positive potential in a terrace hetero $p-n$ junction
}

\author{
Mohd Fairus Ahmad (10 ${ }^{1,2}$, Motoya Suzuki ${ }^{1}$, Toshiyuki Abe ${ }^{3}$ and Keiji Nagai (iD)
}

\begin{abstract}
Generally, $p-n$ junction-based solar energy conversion has the disadvantage of a loss in potential gain in comparison with the photon energy. In this study, we found a more positive potential for a lateral domain interface of $p-n$ junction than for a conventional $p-n$ junction. A terrace bilayer (TB) $p-n$ junction of phthalocyanine $\left(\mathrm{H}_{2} \mathrm{PC}\right)$ and $3,4,9,10-$ perylenetetracarboxylic-bis-benzimidazole (PTCBI) was studied using scanning Kelvin probe microscopy (SKPM), and its electronic properties were analyzed using the contact potential difference $\left(V_{C P D}\right)$ data. The analysis of $V_{C P D}$ in the single layer region and the bilayer region (BLR) indicated a vacuum level shift through the electron transfer from PTCBI into indium tin oxide (ITO), from $\mathrm{H}_{2} \mathrm{PC}$ into ITO and from $\mathrm{H}_{2} \mathrm{PC}$ into PTCBI. Furthermore, the comparison of these $V_{\text {CPD }}$ data indicated a micrometer-localized positive potential in the boundary region (BDR) of the terrace bilayer structure of $p$ type on $n$-type. The gain difference of the $V_{\text {CPD }}$ reached $+0.1 \mathrm{~V}$ in comparison with the BLR. The phenomena can be explained as a lateral dipole at the $p-n$ junction. Similar phenomena were observed in $\mathrm{TB}-\mathrm{H}_{2} \mathrm{PC} / \mathrm{C}_{60} / \mathrm{TTO}$ and TB- $\mathrm{H}_{2} \mathrm{PC} /$ PTCBI/Au. The gain was extracted as oxidation power in photoelectrochemistry; i.e., at $-0.2 \mathrm{~V} v \mathrm{vs} . \mathrm{Ag} / \mathrm{AgCl}$ a greater anodic current was observed for a patterned terrace bilayer electrode. Additionally, as a photocatalyst film (i.e., a $\mathrm{H}_{2} \mathrm{Pc}$ (dot)/PTCBI/PTFE membrane filter), the $p-n$ dot terrace structure showed a higher quantum efficiency (5.1\%) than that of the bilayer (3.2\%) for the decomposition of acetic acid. The present design and method were utilized to obtain an efficient photocatalyst, especially through the mitigation of potential loss from the photon energy to redox powers without changing the molecular component.
\end{abstract}

\section{Introduction}

Organic semiconductor materials (OSMs) have been studied for many photovoltaic applications, such as solar cells $^{1-12}$, through the design and synthesis of new molecules, morphology control ${ }^{1-12}$, and extension to photocatalysts $^{13-19}$. The Fermi level $\left(E_{\mathrm{F}}\right)$ of an OSM is useful for analyzing its characteristics, such as band bending and

\footnotetext{
Correspondence: Keiji Nagai (nagai.k.ae@m.titech.ac.jp)

${ }^{1}$ Laboratory for Chemistry and Life Science, Institute of Innovative Research,

Tokyo Institute of Technology, R1-26, Nagatsuta 4259, Midori-ku, Yokohama 226-8503, Japan

${ }^{2}$ School of Microelectronic Engineering, Kampus Pauh, Universiti Malaysia Perlis, Arau 02600, Malaysia
}

Full list of author information is available at the end of the article. transport performance ${ }^{20-38}$. Scanning Kelvin probe microscopy (SKPM) as a surface potential analysis method is a technique for analyzing the Fermi level of an OSM and strongly affects its photogenerated carriers and open circuit voltage $\left(V_{\mathrm{OC}}\right)$. The SKPM technique can obtain quantitative information about an OSM without high energy photon or vacuum conditions.

In photovoltaic applications, the OSM heterojunction structure has been commonly used to maximize the carrier generation performance during photoirradiation. A disadvantage of $p-n$ junctions is the drastic loss of the exciton energy compared to the energy difference between the edges of the $n$-type conduction band and the

\section{(c) The Author(s) 2018}

(c) (i) Open Access This article is licensed under a Creative Commons Attribution 4.0 International License, which permits use, sharing, adaptation, distribution and reproduction in any medium or format, as long as you give appropriate credit to the original author(s) and the source, provide a link to the Creative Commons license, and indicate if changes were made. The images or other third party material in this article are included in the article's Creative Commons license, unless indicated otherwise in a credit line to the material. If material is not included in the article's Creative Commons license and your intended use is not permitted by statutory regulation or exceeds the permitted use, you will need to obtain permission directly from the copyright holder. To view a copy of this license, visit http://creativecommons.org/licenses/by/4.0/. 
p-type valence band. Although the levels can be tuned by molecular design and synthesis, there is a trade-off relation with a large band gap as well as light absorption of high energy photons. To focus on the charge separation site, the $p-n$ junction interface, we utilize SKPM. Most past research on bulk heterojunctions $(\mathrm{BHJs})$, the morphologies of $p$-type and $n$-type domains, and their interphases focused on investigating the performance of the photovoltaics. Using conductive atomic force microscopy (CAFM), Coffey et al. mapped the morphological photocurrents with a $20 \mathrm{~nm}$ resolution for the $\mathrm{BHJ}$ of MDMO-PPV:PCBM and discussed the significant variation of the short-circuit current, which depended on the local mobility difference due to the $\mathrm{BHJ}^{20}$. Using SKPM, Chiesa et al. discussed the surface potential variation not only for the lateral direction but also for the vertical direction of a solar cell ${ }^{21}$. Other studies clarified the heterojunction domain interface and the domaindependent surface potential $^{22-31}$, while the domain interface potential has not been well investigated.

The present study reveals phenomena of the lateral contact potential difference $\left(V_{\mathrm{CPD}}\right)$ distribution at a greater than $1 \mu \mathrm{m}$ scale based on the heterojunction arrangements. We focus on studying $p-n$ junctions using two terraced-bilayer (TB) structures consisting of a wellknown and typical combination as the photovoltaic ${ }^{39}$ materials, namely, PTCBI and $\mathrm{H}_{2} \mathrm{Pc}$ on an ITO substrate $[\mathrm{PTCBI}=3,4,9,10$-perylenetetracarboxylic-bisbenzimidazole (n-type); $\mathrm{H}_{2} \mathrm{Pc}=29 \mathrm{H}, 31 \mathrm{H}$-phthalocyanine (p-type); indium tin oxide (ITO)]. The combination of phthalocyanine and PTCBI was the first organic photovoltaic $p-n$ junction $^{1,10-12}$ and is stable for photoelectrochemical $^{40-44}$ and photocatalysis ${ }^{14,15}$ processes. Typically, each of the PTCBI and $\mathrm{H}_{2}$ Pc layers had a ca. 50 $\mathrm{nm}$ thickness. As shown in Scheme 1, the two TB samples were in the form of (top layer)/(bottom layer)/ITO. TB$\mathrm{H}_{2} \mathrm{Pc} / \mathrm{PTCBI} / \mathrm{ITO}$ and TB-PTCBI/ $\mathrm{H}_{2} \mathrm{Pc} / \mathrm{ITO}$ denote each of the terraced bilayer samples. The TB samples have a single layer region (SLR), a bilayer region (BLR), and a boundary region (BDR).

In the present SKPM study, we have obtained distinctive lateral $V_{\mathrm{CPD}}$ characteristics at the $\mathrm{BDR}$ of $\mathrm{TB}-\mathrm{H}_{2} \mathrm{Pc} /$ $\mathrm{PTCBI} / \mathrm{ITO}$ and TB-PTCBI $/ \mathrm{H}_{2} \mathrm{Pc} / \mathrm{ITO}$. The lateral distribution of $V_{\mathrm{CPD}}$ had a positive peak for the case of $p$-type on $n$-type structures (i.e., TB- $\mathrm{H}_{2} \mathrm{Pc} / \mathrm{PTCBI} / \mathrm{ITO}$ ) and a gradient for the case of the $n$-type on $p$-type structure (i.e., TB-PTCBI/ $\mathrm{H}_{2} \mathrm{Pc} / \mathrm{ITO}$ ). These two characteristics were also shown in the case of the other $p-n$ combinations of $\mathrm{H}_{2} \mathrm{Pc}$ and fullerene $\mathrm{C}_{60}$ (i.e., TB- $\mathrm{H}_{2} \mathrm{Pc}$ / $\mathrm{C}_{60} / \mathrm{ITO}$ and TB- $\mathrm{C}_{60} / \mathrm{H}_{2} \mathrm{Pc} / \mathrm{ITO}$ ). Based on these observations, we designed terrace dot electrodes and prepared one using vapor deposition with a mask. Using such an electrode, a more negative threshold potential of the photoanodic current was observed. We also utilized the

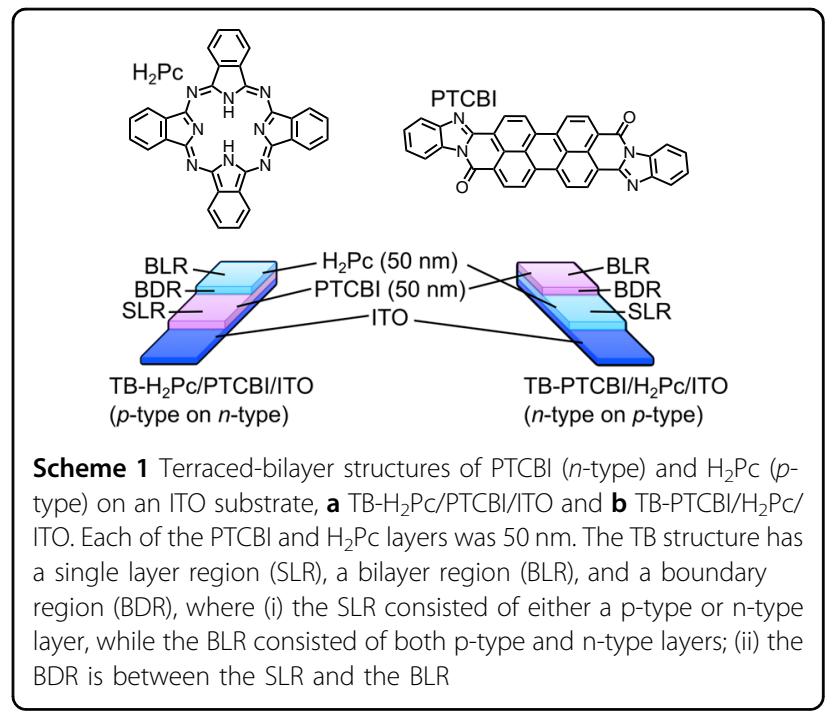

positive potential as an enhanced oxidation power in a photocatalyst application by using the same molecule, based on micrometer geometry control.

\section{Experimental methods \\ Sample preparation}

The ITO glasses (sheet resistance $\leq 15 \Omega /$ sq; transmittance $>85 \%$; ITO thickness $=150 \mathrm{~nm}$; Kuramoto Co., Ltd., Tokyo, Japan.) were cut into a $3 \mathrm{~cm} \times 1 \mathrm{~cm}$ size and cleaned using ultrasonication with acetone and then ethanol. PTCBI was synthesized ${ }^{45}$ and purified according to a previously described procedure ${ }^{46}$. The sublimation of PTCBI was performed in a tubular furnace (ATF350AST3), custom made by Alpha Giken Co. $\mathrm{H}_{2}$ Pc (Tokyo Chemical Industry Co. Ltd.) is commercially available and was purified by sublimation prior to use ${ }^{46} \cdot C_{60}$ (Tokyo Chemical Industry Co. Ltd.) was used as received. PTCBI, $\mathrm{H}_{2} \mathrm{Pc}$ and $\mathrm{C}_{60}$ were individually vapor deposited (using a ULVAC VPC-250) to a ca. $50 \mathrm{~nm}$ thickness at a speed of $0.010 \sim 0.020 \mathrm{~nm} / \mathrm{s}$ and were monitored with a quartz crystal microbalance (QCM) device. Terraced-bilayer samples of $\mathrm{TB}-\mathrm{H}_{2} \mathrm{Pc} / \mathrm{PTCBI} / \mathrm{ITO}$ and TB-PTCBI/ $\mathrm{H}_{2} \mathrm{Pc} /$ ITO were prepared by depositing the second (top) layer of material using a paper mask (RMS edge roughness was $c a$. $7 \mu \mathrm{m}$ ) covering approximately half of the first (bottom) layer area. For the photoelectrochemical study, the bilayer electrode was prepared using vapor deposition as previously described. For the dot pattern terrace bilayer electrode, a shadow mask (nickel, diameter $=200 \mu \mathrm{m}$, pitch $=400 \mu \mathrm{m}, 8 \times 8$ dots, line-edge roughness $=1 \mu \mathrm{m}$ ) was used for the deposition of $\mathrm{H}_{2} \mathrm{Pc}$ on PTCBI. The active area of the electrode was fixed to be $3 \mathrm{~mm} \times 3 \mathrm{~mm}$. For the photocatalyst film preparation $\left(\mathrm{H}_{2} \mathrm{Pc}(50 \mathrm{~nm}) / \mathrm{PTCBI}\right.$ $(50 \mathrm{~nm}) /$ PTFE membrane), commercially available PTFE membrane filters (MILLIPORE, JMWP01300, pore size $=$ 
$5 \mu \mathrm{m}$ and thickness $=80 \mu \mathrm{m}$ ) were used as the substrate for the deposition of the bilayer and dot terrace bilayer structure.

\section{Surface potential measurement}

Samples were measured in the ambient condition using an Asylum Cypher S for atomic force microscopy (AFM) with a controller to stabilize the environment temperature. The operation mode for the SKPM measurement was based on the amplitude modulation (AM) mode ${ }^{47}$. Non-contact mode cantilevers (OCML-AC240TM, OLYMPUS) were used with a typical resonant frequency and a spring constant of approximately $70 \mathrm{kHz}$ and $2 \mathrm{~N} /$ $\mathrm{m}$, respectively. The tip-sample distance and the applied $A C$ voltage were set to $50 \mathrm{~nm}$ and $3 \mathrm{~V}$, respectively. The SKPM images and sectional analysis (Scheme S1) were obtained and processed using a procedure implemented in Igor Pro (Wavemetrics), which is an AFM software controller. The scanning locations of the BLR and the SLR were set at a lateral distance of at least ca. $3-5 \mathrm{~mm}$ from their respective BDR. For the measurement at the BDR, the tip was positioned between the BLR and SLRs within the maximum $30 \mu \mathrm{m}$ size scan area available in our AFM.

A halogen light source (Megalight 100, SCHOTT) was used for irradiation with white light. The light intensity was ca. $9 \mathrm{~mW} / \mathrm{cm}^{2}$.

\section{Photoemission spectroscopy}

To measure the ionization potential (HOMO) of an organic semiconductor, photoemission yield spectroscopy in air (PYSA) was performed using a Riken Keiki AC-3 (photon energy: $4.0 \sim 6.2 \mathrm{eV}$, photon power: $740 \mathrm{~W}$ ). A Riken Keiki AC-2 (photon energy: 3.4-6.2 eV, photon power: $500 \mathrm{nW}$ ) was used to perform PYSA to measure the work function of the ITO and Au/Cr substrates.

\section{Photoelectrochemistry}

The electrochemistry measurement was performed in the dark and under the illumination $\left(70 \mathrm{~mW} / \mathrm{cm}^{2}\right)$ of a halogen lamp (Megalight 100, SCHOTT) whose spectrum of the white light has been shown elsewhere ${ }^{14}$ and under the illumination of a solar simulator (PECCELL PEC-L15) with an intensity of $100 \mathrm{~mW} / \mathrm{cm}^{2}$. The electrolyte was 10 $\mathrm{mM}$ 2-mercaptoethanol in $\mathrm{KOH}$ (pH: 11) unless a different concentration is mentioned in the figure caption. The scan rate was $0.5 \mathrm{mV} / \mathrm{sec}$ unless otherwise stated in the figure caption. A Pt electrode was used as the counter electrode. The reference electrode was a $\mathrm{Ag} / \mathrm{AgCl}$ (in saturated $\mathrm{KCl}$ electrolyte) electrode.

\section{Photocatalysis}

In the photocatalysis study, LED ring lights (PROFOTONIX) with $\lambda=630 \mathrm{~nm}$ were used as a light source. The fabricated photocatalyst films (i.e., $\mathrm{H}_{2} \mathrm{Pc} / \mathrm{PTCBI} / \mathrm{PTFE}$
Table 1 The contact potential difference $\left(V_{\mathrm{CPD}}\right), \varphi_{\text {sample }}$ estimated from Eq. (2), and HOMO level from the vacuum level estimated with PYSA (present study) and UPS (reference) data for the substrate and OSM

\begin{tabular}{|c|c|c|c|c|}
\hline Sample & $V_{\mathrm{CPD}}[\mathrm{V}]$ & $\varphi_{\text {sample }}{ }^{\mathrm{a}}[\mathrm{eV}]$ & PYSA [eV] & UPS [eV] \\
\hline $\mathrm{Au} / \mathrm{Cr}$ & +0.05 & 4.87 & $4.79^{c}$ & $4.79^{48}$ \\
\hline ITO & $-0.08 \sim 0.22$ & $4.70 \sim 5.00$ & $4.69^{c}$ & $\begin{array}{l}4.20 \sim 4.78^{50-52}, \\
4.85 \sim 5.10^{50,51} \\
\left(\mathrm{O}_{2} \text { plasma }\right)\end{array}$ \\
\hline $\mathrm{H}_{2} \mathrm{PC} / \mathrm{Au} / \mathrm{Cr}$ & +0.32 & $\begin{array}{l}4.60 \\
4.44^{58}\end{array}$ & 5.11 & $4.95(\mathrm{on} \mathrm{Au})^{38}$ \\
\hline PTCBI/Au/Cr & +0.17 & $\begin{array}{l}4.75 \\
4.9^{34}\end{array}$ & 6.09 & $6.2(\mathrm{on} A u)^{56}$ \\
\hline $\mathrm{H}_{2} \mathrm{Pc} / \mathrm{ITO}^{\mathrm{b}}$ & +0.17 & 4.75 & 5.32 & \\
\hline PTCBI/ITO & +0.28 & $\begin{array}{l}4.64 \\
4.9^{34}\end{array}$ & 6.06 & \\
\hline
\end{tabular}

${ }^{\mathrm{a}}$ Estimated by Eq. (2). The thickness of the OSM was $50 \mathrm{~nm}$.

bepending on ITO.

'Work function value.

membrane filter) were individually kept in $1 \mathrm{ml}$ of a $3 \mathrm{wt} \%$ aqueous solution of acetic acid in a gas chromatographytype vial (size $1.5 \mathrm{ml}$ ) and irradiated for $1 \mathrm{~h}$ with a light intensity of $1 \mathrm{~mW} / \mathrm{cm}^{2}$. The photocatalytic performance was evaluated using the $\mathrm{CO}_{2}$ generation. The concentration of $\mathrm{CO}_{2}$ generation was monitored using gas chromatography (Shimadzu GC 2014) for vials with and without the presence of a $\mathrm{H}_{2} \mathrm{Pc} / \mathrm{PTCBI} / \mathrm{PTFE}$ membrane filter. The external quantum efficiency of $\mathrm{CO}_{2}$ generation $\left(E Q E_{\mathrm{CO} 2}\right)$ was calculated using:

$$
E Q E(\%)=n N_{A} M \times 100 / \text { IAt },
$$

where $n$ is the number of positive holes needed to produce a $\mathrm{CO}_{2}$ molecule, $N_{A}$ is Avogadro's number (particles $\left.\mathrm{mol}^{-1}\right), M$ is the amount of $\mathrm{CO}_{2}$ generated (in mol), $I$ is the incident photon flux (in photons $\mathrm{cm}^{-2} \mathrm{~s}^{-1}$ ), $A$ is the area of the photocatalyst film (in $\mathrm{cm}^{2}$ ), and $t$ is the irradiation time (in s).

\section{Results and discussion}

Contact potential difference $\left(V_{\mathrm{CPD}}\right)$ analysis of substrates

First, the electrical connection was confirmed, using an independent measurement of the potential difference between the substrates and the electrical ground terminal of the SKPM system, to be ca. $0 \mathrm{~V}(<0.1 \mathrm{mV})$. Next, $V_{\mathrm{CPD}}$ (in V) was measured for the ITO-coated glass and the $\mathrm{Au}$ coated $\mathrm{Cr}$ electrode, which are conducting substrates without the deposited OSMs. Some of the $V_{\mathrm{CPD}}$ mappings are shown in Figure S1 for a $30 \mu \mathrm{m} \times 3 \mu \mathrm{m}$ area, and the average values are summarized in Table 1 . The $V_{\mathrm{CPD}}$ 
values were $0.05 \mathrm{~V}$ and $-0.08 \sim 0.22 \mathrm{~V}$ for $\mathrm{Au}$ on $\mathrm{Cr}$ and ITO, respectively, with a sample-dependent error of \pm 35 $\mathrm{mV}$ and $\pm 150 \mathrm{mV}$. The $V_{\mathrm{CPD}}$ value is the bias potential between the probe $\left(\phi_{\text {probe }}\right)$ and the sample $\left(\phi_{\text {sample }}\right)$ when the coulomb interaction is nullified between them ${ }^{47}$.

$$
V_{C P D}=\left(\phi_{\text {probe }}-\phi_{\text {sample }}\right) / e
$$

For the conductive sample, the $\phi_{\text {sample value (in } \mathrm{eV} \text { ) }}$ should equal the work function $\left(E_{\mathrm{F}}\right.$ in $\left.\mathrm{eV}\right)$. According to previous studies, $\phi_{\text {probe }}=4.92^{48} \sim 5.6^{49}[\mathrm{eV}]$ for Pt-coated $\mathrm{Ir}$, and here, we adopt $\phi_{\text {probe }}=4.92[\mathrm{eV}]$. Then, $\phi_{\text {ITO }}$ and

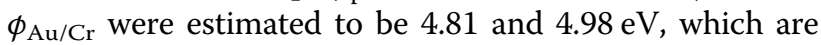
slightly deeper than the work functions of $4.20-4.78 \mathrm{eV}$ (chemically washed ITO) ${ }^{50-53}$ and $4.79 \mathrm{eV}(\mathrm{Au})$, respectively, as shown in Table 1. There have been discussions about the pretreatment effect of $\phi_{\mathrm{ITO}}{ }^{50-53}$, where oxygen plasma cleaning induced a positive shift to $\phi_{\text {IтO }}>5.02$ $\mathrm{eV}^{50-52}$ and a return to $\phi_{\text {ITO }} \sim 5.02 \mathrm{eV}$ upon exposure to air $^{51}$. The present sample difference in $\phi_{\text {ITO }}$ is within the difference discussed in the previous papers.

\section{Contact potential difference $\left(V_{\mathrm{CPD}}\right)$ analysis in the single layer films PTCBI/ITO and $\mathrm{H}_{2} \mathrm{PC} / \mathrm{ITO}$}

Single layer films on ITO, i.e., PTCBI/ITO and $\mathrm{H}_{2} \mathrm{Pc} /$ ITO, were individually prepared, and the contact potential difference was obtained together with topographic images (Figures S2 and S3, respectively). The mean surface roughness of PTCBI was $c a . \pm 5 \mathrm{~nm}$, while that of $\mathrm{H}_{2} \mathrm{Pc}$ was $c a . \pm 10 \mathrm{~nm}$. From the map, a scan line of the contact potential difference was obtained as the average of the rectangular direction (256 pixels) and is shown in Figure S4. The total average contact potential difference on the line was 0.28 and $0.17 \mathrm{~V}$ for PTCBI/ITO and $\mathrm{H}_{2} \mathrm{Pc} /$ ITO, respectively, under the dark condition.

In this work, the error for the samples was ca. $\pm 10 \mathrm{mV}$, as seen in the lines in Figure S4. Generally, for the SKPM measurement, a source of error was the sample-tip probe capacitance due to the geometrical effect of the tip apex ${ }^{54}$. The tip dependence was within the error for the sample above, as shown in Figure S5, where a sample was measured using two different tips of the cantilever. However, the sample dependence of $V_{\mathrm{CPD}}$ was larger than the tip dependence, as shown in Figure S6, for the same type of sample series. Interestingly, the difference in the $V_{\mathrm{CPD}}$ of the sample from that of the substrate did not depend on the samples within the error of $\pm 0.1 \mathrm{~V}$. In this study, we chose ITO having $0.1 \mathrm{~V}<V_{\mathrm{CPD}}<0.2 \mathrm{~V}$.

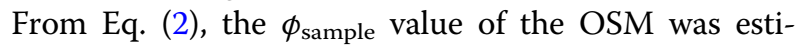
mated to be $4.60 \mathrm{eV}$ for $\mathrm{H}_{2} \mathrm{Pc} / \mathrm{Au}$ and $4.75 \mathrm{eV}$ for PTCBI/ $\mathrm{Au}$, as shown in Table 1 . These $\phi_{\text {sample }}$ values approximately agreed with the previous reports of $4.44 \mathrm{eV}$ for $\mathrm{H}_{2} \mathrm{Pc} / \mathrm{Au}^{51}$ and $4.9 \mathrm{eV}$ for PTCBI/ $/ \mathrm{Au}^{34}$.
In previous studies on phthalocyanines ${ }^{55}$ and $\mathrm{PTCBI}^{56}$ using UPS, the $E_{\mathrm{F}}$ depended on the substrate material, such as a metal or ITO, and was ascribed to more than the factors in the conventional Mott-Schottky model: (1) The Fermi levels were unaligned at the substrate/OSM junction. The nonalignment was discussed in connection with the incorporation of $\mathrm{O}_{2}$ and/or $\mathrm{H}_{2} \mathrm{O}$ into the $\mathrm{OSM}^{32}$. (2) The metal-OSM charge transfer and formation of polaron-like states at the OSM-substrate interface affected the vacuum level shift.

Using PYSA, the HOMO levels were estimated and are shown in Table 1 . When these values were compared with

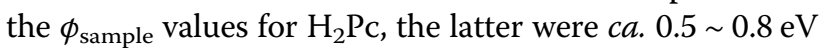
shallower than the HOMO level, while PTCBI exhibited a level that was $c a .1 .3 \sim 1.4 \mathrm{eV}$ shallower than the LUMO level. When $\phi_{\text {sample }}$ is treated as the $E_{\mathrm{F}}$ of the OSM, the difference would agree with the $p$ and $n$ character of $\mathrm{H}_{2} \mathrm{Pc}$ and PTCBI, respectively, for the ambient condition.

Figure 1 shows the electronic energy level for each of the single layer OSMs on ITO. There is a clear shift of $\phi_{\text {sample }}$ for PTCBI/ITO and $\mathrm{H}_{2} \mathrm{Pc} / \mathrm{ITO}$, suggesting that the vacuum level shift is $0.24-0.25 \mathrm{eV}^{32}$. For the OSMs, a thickness dependence of $\phi_{\text {sample }}$ was observed for both PTCBI/ITO and $\mathrm{H}_{2} \mathrm{Pc} / \mathrm{ITO}$. The PYSA data for the thickness-dependent samples indicated that the HOMO level of $\mathrm{H}_{2} \mathrm{Pc} / \mathrm{ITO}$ shifted, while that of PTCBI/ITO did not.

Under illumination, $V_{\mathrm{CPD}}$ shifted for PTCBI/ITO (20 $\mathrm{mV})$, while that for $\mathrm{H}_{2} \mathrm{Pc} / \mathrm{ITO}$ only slightly shifted $(-10$ $\mathrm{mV}$ ), as shown in Figure S4. Itoh et al. found a similar slight positive shift for $\mathrm{C}_{60} / \mathrm{ITO}$ and no change for $\mathrm{CuPc} /$ ITO under light illumination. The difference between the $p$-and $n$-type characters might induce the shift of $V_{\mathrm{CPD}}$ by light-induced electron transfer from the OSM to ITO $^{37}$.

\section{Contact potential difference $\left(V_{\mathrm{CPD}}\right)$ analysis in a SLR of the TB samples}

From here, we discuss the $V_{\mathrm{CPD}}$ characteristics in the terraced-bilayer $(\mathrm{TB})$ structure. Scan lines of $V_{\mathrm{CPD}}$ are shown in Fig. 2 for both TB- $\mathrm{H}_{2} \mathrm{Pc} / \mathrm{PTCBI} / \mathrm{ITO}$ and TBPTCBI $/ \mathrm{H}_{2} \mathrm{Pc} / \mathrm{ITO}$, in which the region consisted of either PTCBI $(50 \mathrm{~nm})$ or $\mathrm{H}_{2} \mathrm{Pc}(50 \mathrm{~nm})$ on the ITO substrate. For each of the SLRs (Fig. 2a, b, SLR), the $V_{\mathrm{CPD}}$ value of TB- $\mathrm{H}_{2} \mathrm{Pc} / \mathrm{PTCBI} / \mathrm{ITO}(0.40 \mathrm{~V})$ was more positive than that of TB-PTCBI/ $\mathrm{H}_{2} \mathrm{Pc} / \mathrm{ITO}(0.24 \mathrm{~V})$, similar to those of the simple single layer samples (Figure S4).

\section{Contact potential difference $\left(V_{\mathrm{CPD}}\right)$ analysis in the BLR of the TB samples}

Figure 2c, d show the 128 pixel-averaged $V_{\mathrm{CPD}}$ for parts of each BLR of TB- $\mathrm{H}_{2} \mathrm{Pc} / \mathrm{PTCBI} / \mathrm{ITO}$ and TB-PTCBI/ $\mathrm{H}_{2} \mathrm{Pc} / \mathrm{ITO}$, respectively, and the $V_{\mathrm{CPD}}$ values are $0.54 \mathrm{~V}$ and $-0.02 \mathrm{~V}$. The $\phi_{\text {sample }}$ values were estimated using Eq. (2) as $\phi_{\mathrm{H} 2 \mathrm{Pc} / \mathrm{PTCBI}}=4.38 \mathrm{eV}$ and $\phi_{\mathrm{PTCBI} / \mathrm{H} 2 \mathrm{Pc}}=4.94 \mathrm{eV}$. 
(a)

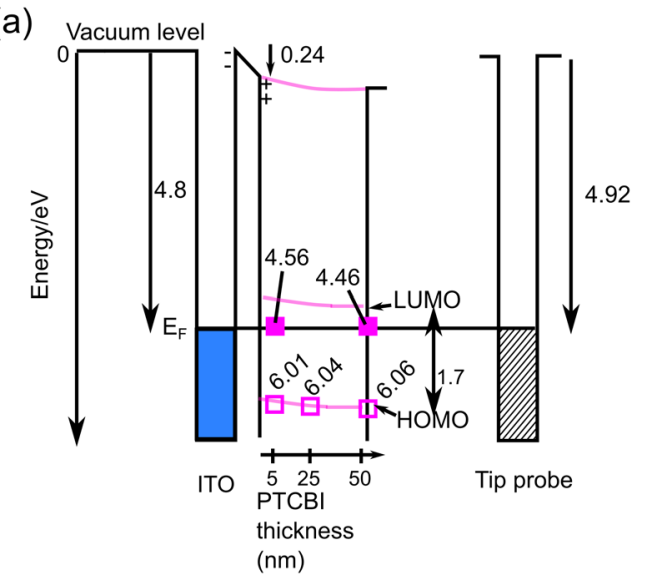

(b)

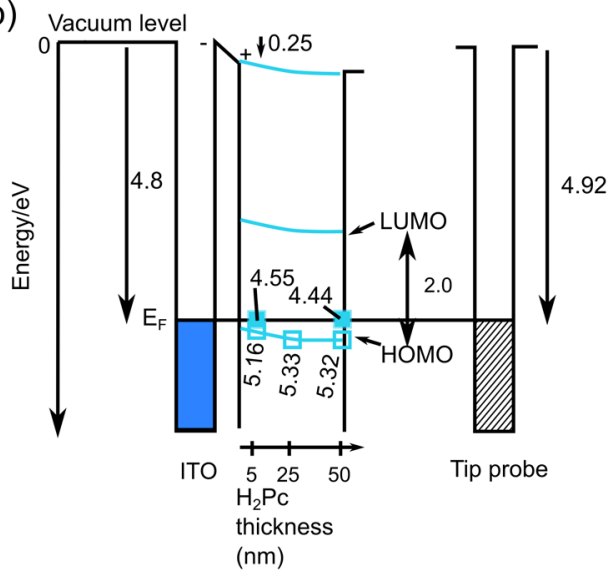

Fig. 1 Electronic structure for PTCBI/ITO and $\mathrm{H}_{2} \mathrm{Pc} / \mathrm{ITO}$ with the HOMO level observed using PYSA and the $\varphi_{\text {sample }}$ values in the dark. At the ITO/OSM interface, a vacuum level shift was assumed based on the difference between $\varphi_{\text {sample }}$ and $\varphi_{\text {ITO }}$
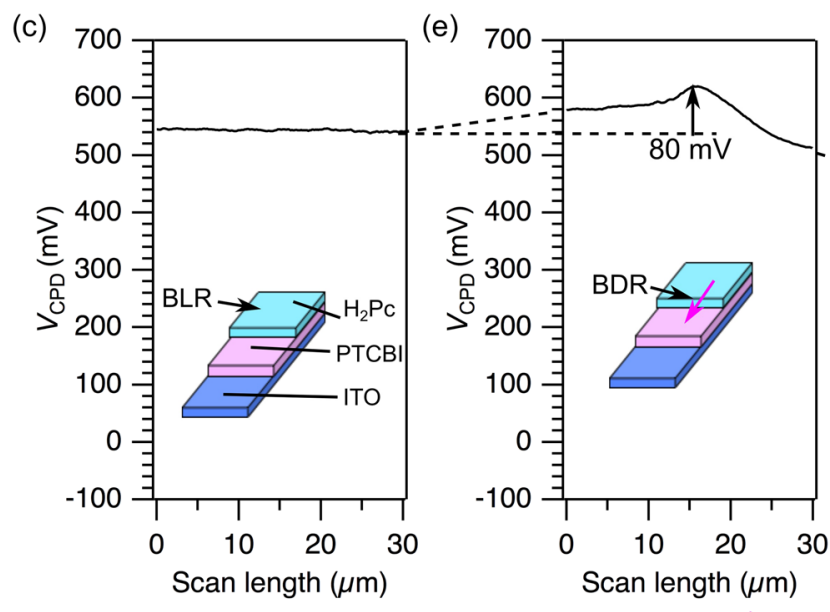

BLR $\longrightarrow$ SLR

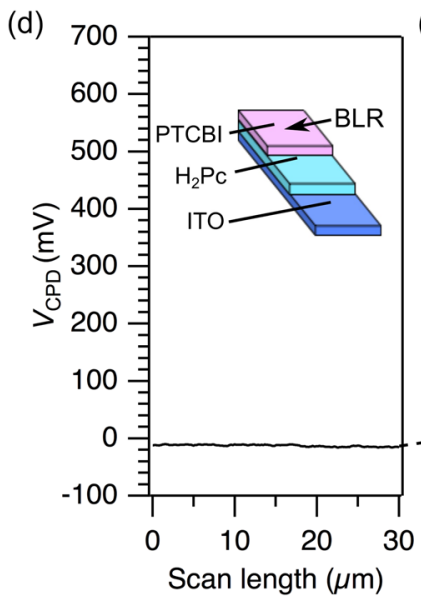

(f)

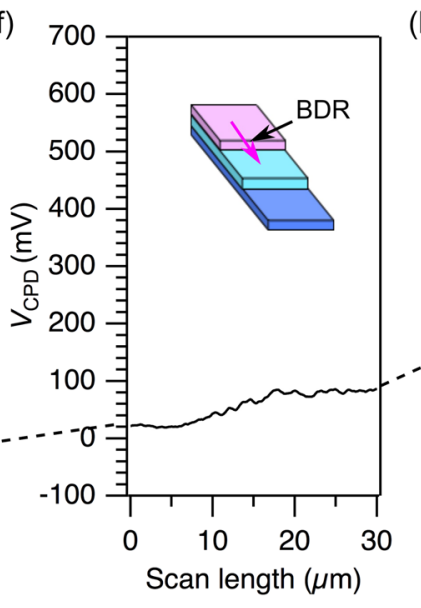

$\mathrm{BLR} \longrightarrow \mathrm{SLR}$ (a)

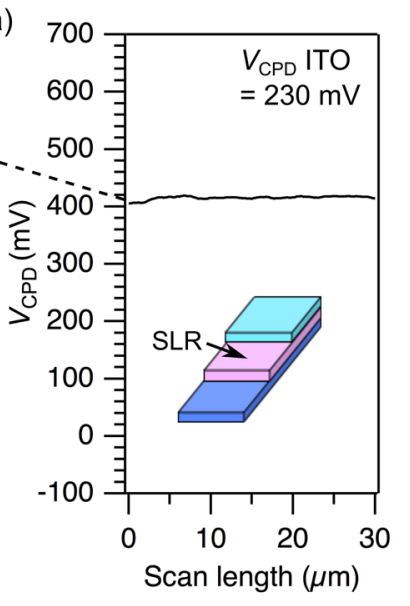

(b)

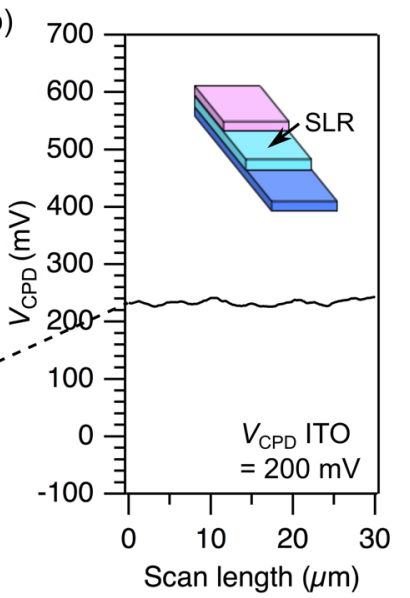

Fig. 2 Lateral $V_{\text {CPD }}$ in TB- $H_{2}$ Pc/PTCBI/ITO and TB-PTCBI/ $\mathbf{H}_{2}$ Pc/ITO under the dark condition. a, b single layer region (SLR), $\mathbf{c}, \mathbf{d}$ bilayer region $(B L R)$ and $\mathbf{e}, \mathbf{f}$ boundary region (BDR). Purple arrows at the bottom in $(\mathbf{e}, \mathbf{f})$ indicate the directions of the BLR to the SLR. The scanning locations of the SLR and BLR were set at a lateral distance of at least ca. 3-5 mm from their BDR, and the detailed distance is shown in Fig. 5. The vertical arrow in (e) indicates the amplification in the BDR (ca. $80 \mathrm{mV}$ ) 

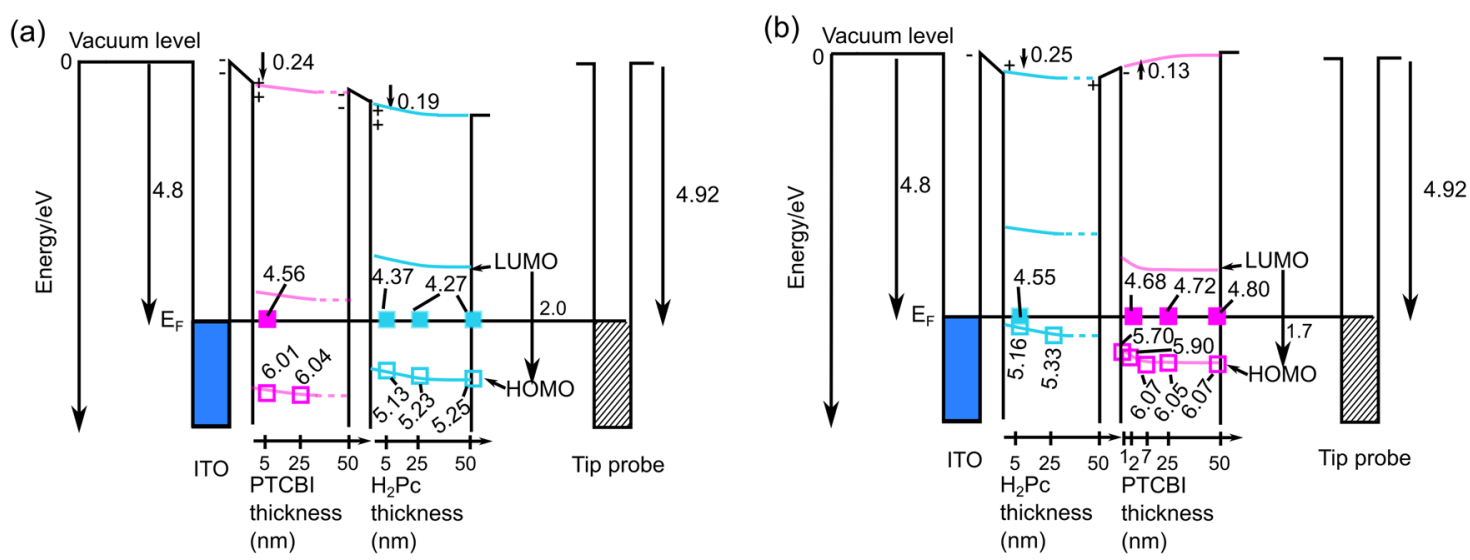

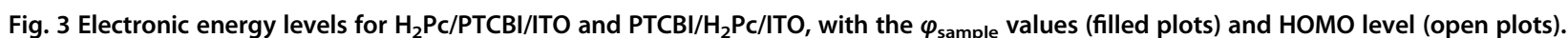
For the bottom layer, the values are the same as those of the single layer shown in Fig. 1. For the top layer, these values were obtained for the thickness-dependent bilayer samples

These $V_{\mathrm{CPD}}$ and $\phi_{\text {sample }}$ values are very different from those of single layers and imply an effect on the OSM as a substrate. Notably, the differences of the $\phi_{\text {sample }}$ values between the single and BLRs are coincidently $0.2 \mathrm{~V}$ for both cases; i.e.,

$$
\begin{aligned}
& \phi_{\mathrm{H} 2 \mathrm{Pc} / \mathrm{PTCBI}}-\phi_{\mathrm{PTCBI}} \approx-0.2[e V] \\
& \phi_{\mathrm{PTCB} / \mathrm{H} 2 \mathrm{Pc}}-\phi_{\mathrm{H} 2 \mathrm{Pc}} \approx 0.2[\mathrm{eV}]
\end{aligned}
$$

The above difference appears consistent with the same potential shift at the $\mathrm{H}_{2} \mathrm{Pc} / \mathrm{PTCBI}$ interface. Here, again, we have prepared a series of thickness-dependent samples for the top layer and measured them using both PYSA and SKPM. The data are shown in Fig. 3. The plots of the HOMO level are obtained using the PYSA experiments for the thickness-dependent bilayers. Because the surface of the bottom layer in the BLR is not exposed to air, the plots are not shown for the bottom layer at the $p-n$ junction, and the energy levels are drawn as dotted lines. Based on Eq. (2), $\phi_{\text {sample }}$ can be estimated, as shown in the filled plots. For $\mathrm{H}_{2} \mathrm{Pc}$ on PTCBI, i.e., the top layer, $\phi_{\mathrm{H} 2 \mathrm{Pc} /}$ PTCBI was much shallower than that in the single layer, $\phi_{\mathrm{H} 2 \mathrm{Pc}}$, while for PTCBI on $\mathrm{H}_{2} \mathrm{Pc}, \phi_{\mathrm{PTCB} / \mathrm{H} 2 \mathrm{Pc}}$ was deeper than that of $\phi_{\mathrm{PTCBI}}$. These shifts are consistent with electron transfer from p-type to n-type. For the top layer, both the PYSA and SKPM measurements indicated band bending for the cases of both $\mathrm{H}_{2} \mathrm{Pc} / \mathrm{PTCBI} / \mathrm{ITO}$ and $\mathrm{PTCBI} / \mathrm{H}_{2} \mathrm{Pc} / \mathrm{ITO}$. Interestingly, the observation of the vacuum level shift was not consistent for the two bilayer samples, i.e., from PTCBI to $\mathrm{H}_{2}$ Pc for $\mathrm{H}_{2} \mathrm{Pc} / \mathrm{PTCBI} / \mathrm{ITO}$ and from $\mathrm{H}_{2} \mathrm{Pc}$ to PTCBI for PTCBI/ $\mathrm{H}_{2} \mathrm{Pc} / \mathrm{ITO}$. Similar asymmetric phenomena were reported in $\mathrm{C}_{60} / \mathrm{H}_{2} \mathrm{Pc} / \mathrm{Au}$ and $\mathrm{H}_{2} \mathrm{Pc} / \mathrm{C}_{60} / \mathrm{Au}$ by Ishii et al. ${ }^{38}$.

Such a description is not simplified as described in Eqs. (3) and (4), as is apparent from the $\phi_{\mathrm{PTCBI}}$ for the $50 \mathrm{~nm}$ top layer. At the $p-n$ junction, the vacuum level shift from p-type to n-type can be drawn if we assume a flat energy level for the bottom layer, such as the dotted line shown in Fig. 3, even in the dark.

From a separate experiment, Figures $\mathrm{S} 7 \mathrm{c}$ and d show the data taken under illumination, where $V_{\mathrm{CPD}}$ of the BLR shifted to a deep level for TB- $\mathrm{H}_{2} \mathrm{Pc} / \mathrm{PTCBI} / \mathrm{ITO}$, while it shifted little for TB-PTCBI $/ \mathrm{H}_{2} \mathrm{Pc} / \mathrm{ITO}$. In the cases of the single layer, PTCBI/ITO showed a shift, while $\mathrm{H}_{2} \mathrm{Pc} / \mathrm{ITO}$ did not (Figure S4). The difference between the bilayers is due to a similar reason as for the electron transfer from the OSM to ITO seen in the SLR.

\section{Contact potential difference $\left(V_{\mathrm{CPD}}\right)$ in the BDR of the TB samples}

Figure 2e shows a positive peak of the $V_{\mathrm{CPD}}$ value in the $\mathrm{BDR}$ of TB- $\mathrm{H}_{2} \mathrm{Pc} / \mathrm{PTCBI} / \mathrm{ITO}$. $V_{\mathrm{CPD}}$ was continuous from the far SLR to the far BLR, as shown in Fig. $4 \mathrm{~d}$ (green line). The amplification in the BDR $(0.62 \mathrm{~V})$ from the BLR $(0.54$ $\mathrm{V})$ was $+0.08 \mathrm{~V}$, i.e., $0.62-0.54=+0.08 \mathrm{~V}$, under the dark condition. The BDR of TB-PTCBI/ $\mathrm{H}_{2} \mathrm{Pc} / \mathrm{ITO}$ (Fig. 2f) showed no amplification.

As shown in Figure S7e (red line), under illumination, the $V_{\mathrm{CPD}}$ characteristics at the BDR of TB- $\mathrm{H}_{2} \mathrm{Pc} / \mathrm{PTCBI} /$ ITO showed a positive peak similar to that in the dark and had a shift to a more positive potential. For the BDR of TB-PTCBI $/ \mathrm{H}_{2} \mathrm{Pc} / \mathrm{ITO}$, as shown in Figure S7f (red line), the $V_{\mathrm{CPD}}$ shift at the BDR was small. Such a bottom layer dependence was similar for the cases of the SLR and BLR.

In the case of the $\mathrm{Au} / \mathrm{Cr}$ substrate, $V_{\mathrm{CPD}}$ had a similar peak, as shown in Figure S8, which supports that the present peak is due to the $p-n$ junction not the substrate, such as ITO or Au. On the other hand, the $\phi_{\text {sample }}$ values for a single layer on $\mathrm{Au} / \mathrm{Cr}$ were different from the cases with an ITO substrate, while the apparent relation shown 


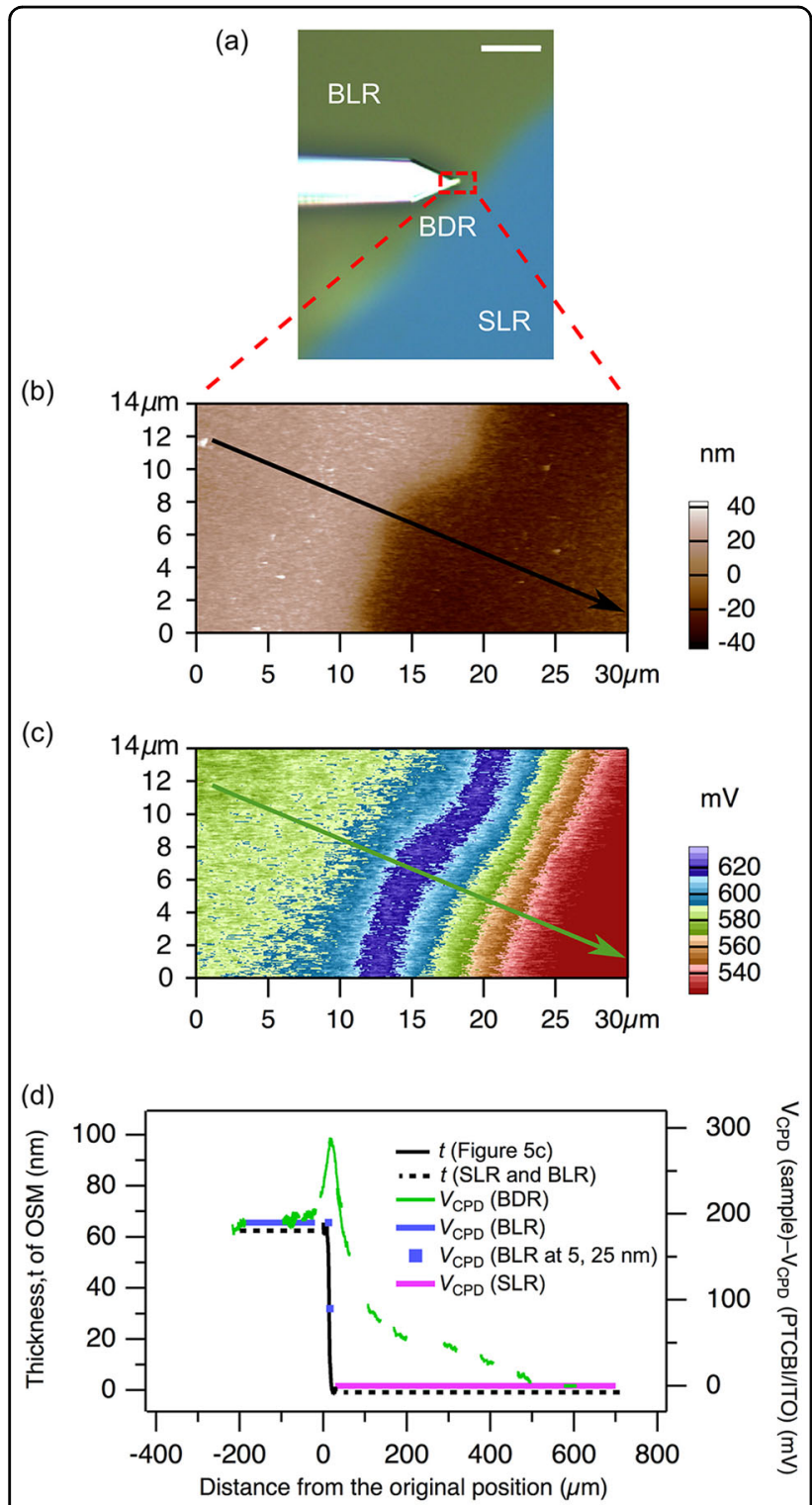

Fig. 4 a Optical image of the cantilever positioning (white scale bar = $50 \mu \mathrm{m})$ at the BDR. This position is referred as the original position. $\mathbf{b}$ Topography image at the BDR. c SKPM data for the same area as in (b) where the $V_{C P D}$ peak was observed. $\mathbf{d} V_{C P D}$ (green line) value on the green arrow in (c) and the extended area from $-200 \mu \mathrm{m}$ in the BLR to $+700 \mu \mathrm{m}$ in the SLR (not fully measured). The $V_{C P D}$ values for the SLR (purple line) and the BLR (blue line, blue square plots) were obtained for another step sample. These $V_{C P D}$ values are relative to the $V_{C P D}$ of PTCBI/ITO. The thicknesses of the OSM ( $t$ ) (black line) correspond to the sectional data in (b) and are relative to the SLR thickness. The dashed black line in (d) is the extrapolation of $t$ to the BLR and SLR. Note that the TB- $\mathrm{H}_{2} \mathrm{PC} / \mathrm{PTCBI} / \mathrm{ITO}$ sample is different from that in Fig. 2

in Eqs. (3) and (4) was observed for both $\mathrm{TB}-\mathrm{H}_{2} \mathrm{Pc} /$ $\mathrm{PTCBI} / \mathrm{Au} / \mathrm{Cr}$ and $\mathrm{TB}-\mathrm{PTCBI} / \mathrm{H}_{2} \mathrm{Pc} / \mathrm{Au} / \mathrm{Cr}$ in the dark, as well as when they were illuminated.
To investigate these $V_{\mathrm{CPD}}$ characteristics at the BDR for another combination of the $p-n$ junction in the TB samples, TB- $\mathrm{H}_{2} \mathrm{Pc} / \mathrm{C}_{60} / \mathrm{ITO}$ and $\mathrm{TB}-\mathrm{C}_{60} / \mathrm{H}_{2} \mathrm{Pc} / \mathrm{ITO}$ $\left(\mathrm{C}_{60}=\right.$ fullerene molecule, $n$-type $)$ were fabricated. The SKPM measurement (in Figure S9) showed that the BDR of TB- $\mathrm{H}_{2} \mathrm{Pc} / \mathrm{C}_{60} /$ ITO and TB- $\mathrm{C}_{60} / \mathrm{H}_{2} \mathrm{Pc} / \mathrm{ITO}$ also had the lateral distribution of $V_{\mathrm{CPD}}$ of a positive peak and gradient characteristics, respectively, for their structures of TB-ptype/n-type/ITO and TB-n-type/p-type/ITO. These data showed that the peak is due to the terrace bilayer structure with $p$-type on $n$-type.

Figure $4 \mathrm{a}$ shows an optical image of the cantilever placed in proximity to the BDR between the SLR and the BLR of the TB sample. The structure of the cantilever was that the tip of the probe was located at the exact end of the cantilever so that the tip was easily positioned. Figure $4 \mathrm{~b}, \mathrm{c}$ show the topography and $V_{\mathrm{CPD}}$ mapping, respectively, in the BDR of TB- $\mathrm{H}_{2} \mathrm{Pc} / \mathrm{PTCBI} / \mathrm{ITO}$.

The maximum $V_{\mathrm{CPD}}$ value $(\sim 620 \mathrm{mV})$ spanned the boundary (Fig. 4d). Generally, when discussing the $V_{\mathrm{CPD}}$ value, we must treat it is a weighted average of a certain region below the tip due to the finite tip size. The spatial resolution of SKPM is lower than that of AFM due to the difference between the long-range electrostatic force and the short-range van der Waals force. This problem is discussed by Sadewasser et al. in detail, especially for groove structures and step structures ${ }^{54}$, the latter of which is the same as the present topic. According to the study, the peak height of the signal of the $V_{\mathrm{CPD}}$ value was $\sim 60 \%$ of the input $V_{\mathrm{CPD}}$ value, with broadening of the FWHM being linear against the input space charge region of 50 $200 \mathrm{~nm}$ with $100 \mathrm{meV}$ of contact potential difference for the $50 \mathrm{~nm}$ tip-sample distance. Additionally, for the step substrate, broadening of the contact potential difference more than that of topography was simulated, with $a<10$ $\mathrm{nm}$ shift (output of the simulation) of the step border area to the lower step area for a $5 \mathrm{~nm}$ tip-sample distance (input of the simulation). Then, in this present study, by assuming the linearity between the potential and the tipsample distance $(50 \mathrm{~nm})$, the broadening of the spatial resolution might be $50 \mathrm{~nm}$, which is less than the width of the spatial resolution for the potential peak observed here $(\sim 10 \mu \mathrm{m}$ in Figs. $2 \mathrm{e}$ and $4 \mathrm{~d})$. This means that the $10 \mu \mathrm{m}$ width of the peak is not an artificial error.

The topographical step may affect the local $V_{\mathrm{CPD}}$ as a real and/or artifactual peak. The present step has a slope. To evaluate the effect, a control TB- $\mathrm{H}_{2} \mathrm{Pc} / \mathrm{H}_{2} \mathrm{Pc} / \mathrm{ITO}$ homo junction terrace bilayer sample was prepared independently, and both the topography and $V_{\mathrm{CPD}}$ value (Figure S10) were measured. The $V_{\mathrm{CPD}}$ data of Figure S10, C3 and D3 show that there were no $V_{\mathrm{CPD}}$ peaks, irrespective of the slope steepness, and show that the $V_{\mathrm{CPD}}$ peak observed in Fig. 2e, c was due to the terrace bilayer 
structure with $p$-type on $n$-type. This fact means that the present peak is not an artifact due to the step structure.

Moreover, to investigate whether the peak is or is not due to the steep step morphology, another control sample was fabricated to be a planar $p-n$ junction with small angle crossing of $\mathrm{H}_{2} \mathrm{Pc}$ and PTCBI. As shown in Figure S11, the topography and the SKPM data were measured along the single layer PTCBI to the single layer $\mathrm{H}_{2}$ Pc. The data (for Figure S11, b and e, black filled circle) show that there was a $V_{\mathrm{CPD}}$ peak that reached $650 \mathrm{mV}$ near the flat area (i.e., planar $p-n$ structure). This demonstrates that a $V_{\mathrm{CPD}}$ peak can also occur in a planar $p-n$ structure and is not due to the steep morphology.

There have been reports of applying SKPM for the study of the peak $V_{\text {CPD }}$ at the edge of an OSM crystal ${ }^{21,57}$. Sadewasser et al. simulated the peak $V_{\mathrm{CPD}}$ using a model of the space charge region ${ }^{54}$, for which the width and carrier concentration determine the peak potential value and width observed. The observed peak values were simulated to be approximately half $(40-60 \mathrm{mV})$ of the real potential value $(100 \mathrm{mV})$.

In a typical photovoltaic device, the $p-n$ junction direction is normal to the two electrodes, and then, the potential changes to the normal direction due to the space charge region, surface dipoles, etc. In such a case, the potential difference should be observed as being thickness dependent. We try to interpret the $V_{\mathrm{CPD}}$ in the BDR of TB- $\mathrm{H}_{2} \mathrm{Pc} / \mathrm{PTCBI} / \mathrm{ITO}$ as a thickness-dependent $V_{\mathrm{CPD}}$. In Fig. $4 \mathrm{~d}$, the topography at the BDR is shown, and the thickness of $\mathrm{H}_{2} \mathrm{Pc}$ is from zero to $50 \mathrm{~nm}$. The thicknessdependent $V_{\mathrm{CPD}}$ values are the purple-filled plots, which also do not have a peak and are different from the $V_{\mathrm{CPD}}$ in the BDR (Fig. 4d, green solid line). In comparison, it is impossible to interpret the $V_{\mathrm{CPD}}$ peak at the BDR as a thickness-dependent $V_{\mathrm{CPD}}$ due to the normal direction of the potential changing based on the lateral component of the $p-n$ junction on the substrate.

Considering these results, a reasonable interpretation is that the $V_{\mathrm{CPD}}$ peak originates from the localization of positive charges due to the lateral component of the $p-n$ junction, where the charge transfer occurs not only in the substrate's normal direction but also in the lateral direction. As a result of such a lateral polarization, a positive peak might occur in the BDR, as shown in Fig. 5.

If the potential maximum at the BDR is real, then the potential maximum would give a favorable oxidation power. In a practical application, the greatest output is desired. Additionally, not only a positive $V_{\mathrm{CPD}}$ peak but also a considerable quantum efficiency, typically IPCE, defined as the current per incident light, is required. To confirm the lateral potential maximum effect, we have prepared electrodes with more terraces and more BDRs using vapor deposition with a mask, as shown in Figure $\mathrm{S} 12$. The positive $V_{\mathrm{CPD}}$ peak lay within the

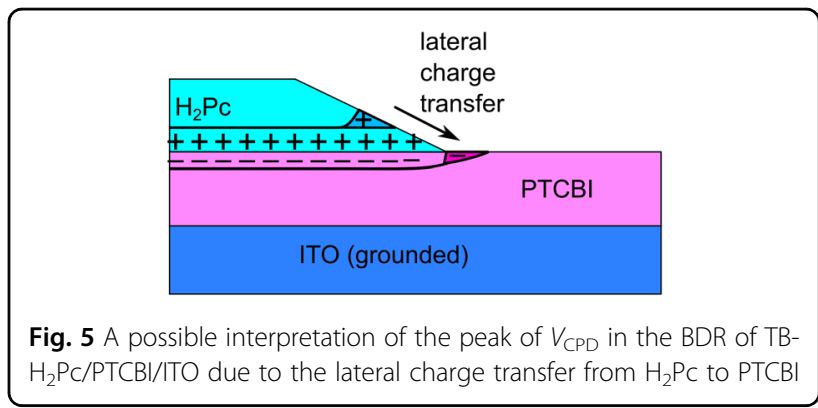

micrometer-wide BDR, as expected based on the previous discussion. In addition to the $V_{\mathrm{CPD}}$ measurement, we performed PYSA experiments and obtained a more positive ionization potential value of $5.27 \mathrm{eV}$.

Figure 6a shows the $I-V$ curve of an electrode designed with more BDRs and prepared using vapor deposition with the mask. The new electrode was compared with the simple bilayer electrode (Fig. 6b) and the terrace bilayer with a controlled area ratio between $\mathrm{PTCBI} / \mathrm{H}_{2} \mathrm{Pc}$ BLR ( 20\%) and PTCBI SLR ( 80\%) (Fig. 6c). In the absence of incident light, no current was observed, while a photoanodic current was observed for all of the cases shown in Fig. 6. The trend was the same as in previous studies, i.e., photoelectrochemical oxidation of thiol occurred under illumination, while no conduction occurred in the dark ${ }^{40}$. The designed and patterned electrode exhibited a more negative threshold potential $(\sim-0.2 \mathrm{~V}$, seen in Fig. 6a, red) for the photoanodic current. The threshold potential was $\sim 0.1 \mathrm{~V}$ less positive than those for the conventional bilayer and terraced bilayer $(\sim-0.1 \mathrm{~V}$, seen in Fig. $6 \mathrm{~b}, \mathrm{c}$, red). Figure 7 shows the light on/off response at the bias potential of $-0.2 \mathrm{~V}$ vs. $\mathrm{Ag} / \mathrm{AgCl}$, which is at the threshold potential of the dot terrace bilayer electrode. Among these electrodes, only the design-patterned electrode exhibited a photoanodic current. In a separate experiment, the bilayer and the dot terrace electrodes were tested under a solar simulator (intensity $=1$ sun or $100 \mathrm{~mW} / \mathrm{cm}^{2}$ ), with double the concentration of donor molecule $(20 \mathrm{mmol}$ $\mathrm{dm}^{-3}$ ) and at the bias potential of $+0.1 \mathrm{~V}$ vs. $\mathrm{Ag} / \mathrm{AgCl}$. Figure S13 shows that the photocurrent of the dot terrace electrode was enhanced by $\sim 30 \mu \mathrm{A} / \mathrm{cm}^{2}$ compared with that of the bilayer.

From these results, it was confirmed that the positive $V_{\mathrm{CPD}}$ peak at the BDR can be utilized for macroscopic photoanodic current generation with a lower negative bias potential.

Figure 8 shows the action spectra of the photoanodic current at $0 \mathrm{~V}$ vs. $\mathrm{Ag} / \mathrm{AgCl}$. At such a small bias potential, the IPCE is at a small $<1 \%$ level, while the dot sample shows a value of $\sim 4 \%$. In addition to the greater external quantum efficiency for the design-patterned electrode, the shape of the spectrum is different from that for the conventional bilayer. The results of the control experiment of 
(a)

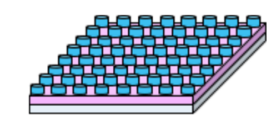

$\mathrm{H}_{2} \mathrm{PC}: \mathrm{PTCBI}=20 \%: 80 \%$

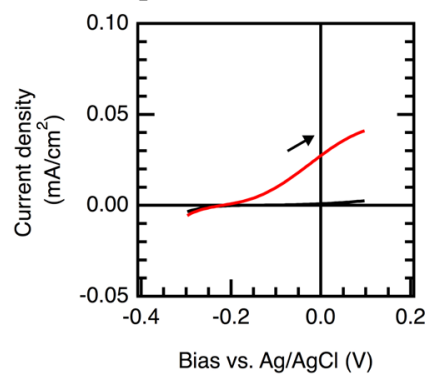

(b)
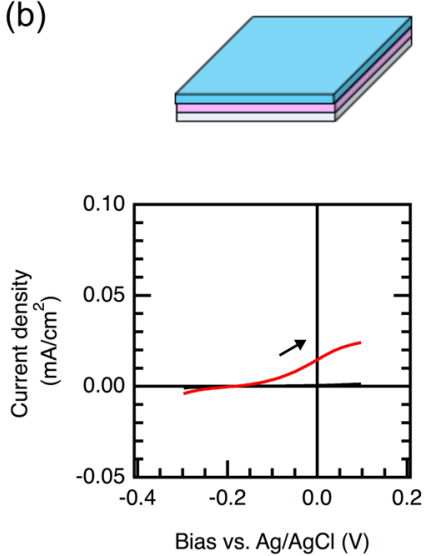

(c)

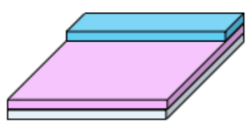

$\mathrm{H}_{2} \mathrm{Pc}: \mathrm{PTCBI}=20 \%: 80 \%$

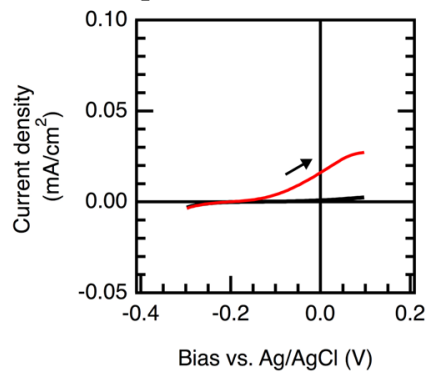

Fig. 6 Voltammetry under dark (black line) and illuminated (red line) conditions for (a) dot-patterned TB- $\mathrm{H}_{2}$ PC/PTCBI/ITO $(8 \times 8$ dot pattern of the $\mathrm{H}_{2} \mathrm{Pc}$ layer on the PTCBI layer, diameter of each $\mathrm{H}_{2} \mathrm{Pc}$ dot $=200 \mu \mathrm{m}$, pitch $=200 \mu \mathrm{m}$; area ratio for $\left.\mathrm{H}_{2} \mathrm{Pc}: \mathrm{PTCB}=1: 4\right)$. b $\mathrm{H}_{2} \mathrm{PC} / \mathrm{PTCB} / / \mathrm{TO}$ (bilayer), and c TB- $\mathrm{H}_{2} \mathrm{PC} / \mathrm{PTCBI} / \mathrm{TOO}\left(\mathrm{H}_{2} \mathrm{Pc}\right.$ dimension $=0.3 \mathrm{~cm} \times 0.058 \mathrm{~cm}$, area ratio for $\left.\mathrm{H}_{2} \mathrm{PC}: \mathrm{PTCBI}=1: 4\right)$. TB terraced bilayer. Effective electrode area $=$ $0.3 \mathrm{~cm} \times 0.3 \mathrm{~cm}$. The thickness for both PTCBI and $\mathrm{H}_{2} \mathrm{PC}$ was $50 \mathrm{~nm}$. Scan rate $=0.5 \mathrm{mV} / \mathrm{sec}$. Electrolyte: $\mathrm{KOH}(\mathrm{pH} 11)$ and $10 \mathrm{mM} 2-\mathrm{mercaptoethanol}$. Light irradiation was from the ITO side using a halogen light source $\left(70 \mathrm{~mW} / \mathrm{cm}^{2}\right)$

(a)

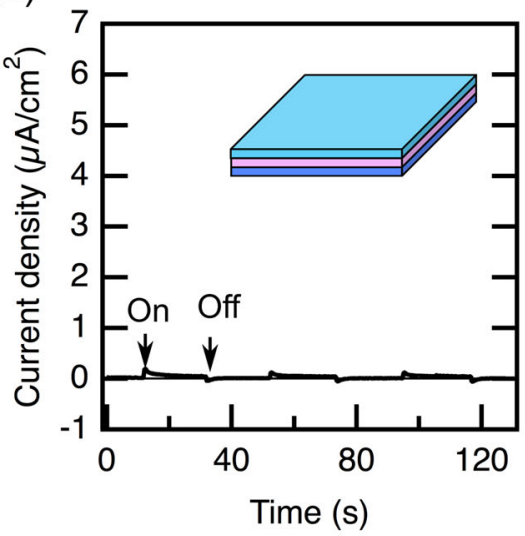

(c)

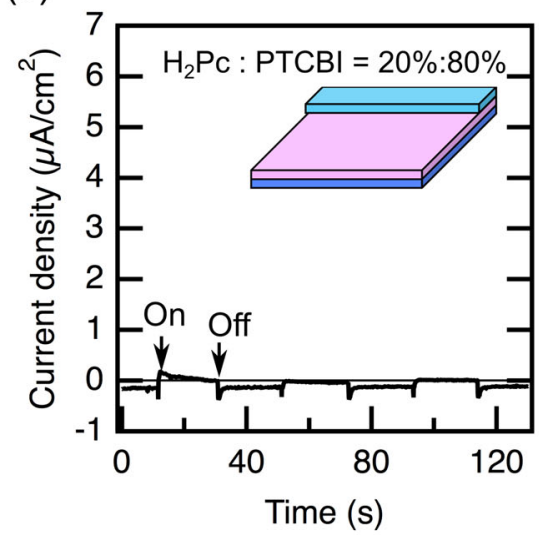

(b)

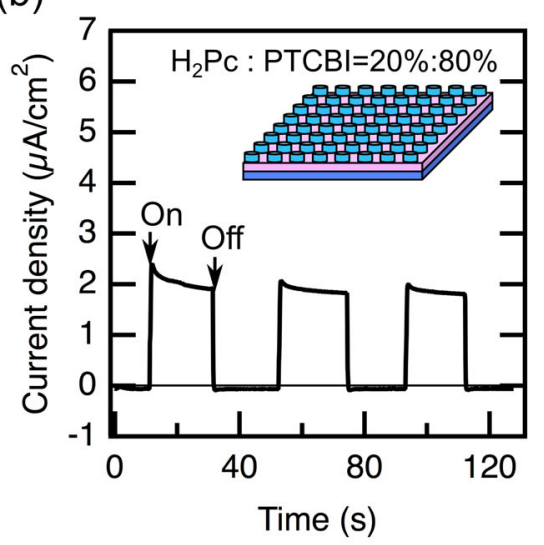

(d)

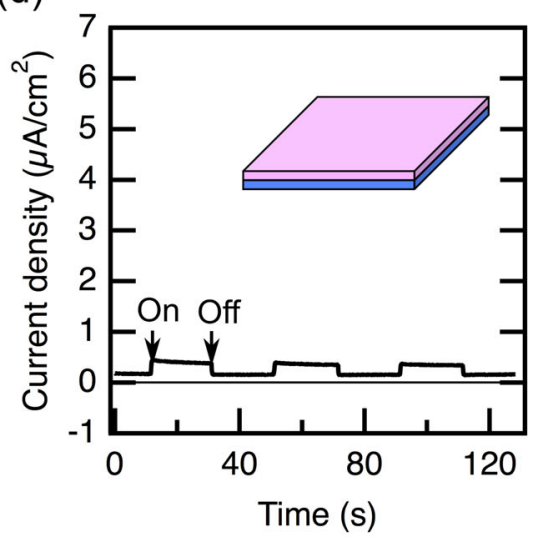

Fig. 7 Transient photocurrent generated at $-0.2 \mathrm{~V}$ (vs. Ag/AgCl) for (a) typical bilayer $\mathrm{H}_{2} \mathrm{PC} / \mathrm{PTCBI} / \mathrm{ITO}$, b dot terraced bilayer $\mathrm{H}_{2} \mathrm{PC} / \mathrm{PTCBI} / \mathrm{TO}(8 \times 8$ dot pattern of the $\mathrm{H}_{2} \mathrm{PC}$ layer on the PTCBI layer, diameter of each $\mathrm{H}_{2} \mathrm{PC}$ dot $=200 \mu \mathrm{m}$, pitch $=200 \mu \mathrm{m}$; area ratio for $\mathrm{H}_{2} \mathrm{PC}: \mathrm{PTCBI}=20 \%: 80 \%$ ), c terraced bilayer $\mathrm{H}_{2} \mathrm{PC} / \mathrm{PTCBI} / \mathrm{TO}\left(\mathrm{H}_{2} \mathrm{PC}\right.$ dimension $=0.3 \mathrm{~cm} \times 0.058 \mathrm{~cm}$, area ratio for $\left.\mathrm{H}_{2} \mathrm{PC}: \mathrm{PTCBI}=20 \%: 80 \%\right)$, and $\mathbf{d}$ single layer PTCBI/ITO. Effective electrode area $=0.3 \mathrm{~cm} \times 0.3 \mathrm{~cm}$. The thicknesses for PTCBI and $\mathrm{H}_{2} \mathrm{Pc}$ were 50 and $150 \mathrm{~nm}$, respectively. Electrolyte: $\mathrm{KOH}(\mathrm{pH} 11)+10 \mathrm{mM} 2-$ mercaptoethanol. Light irradiation was from the ITO side using a halogen light source $\left(70 \mathrm{~mW} / \mathrm{cm}^{2}\right)$ 

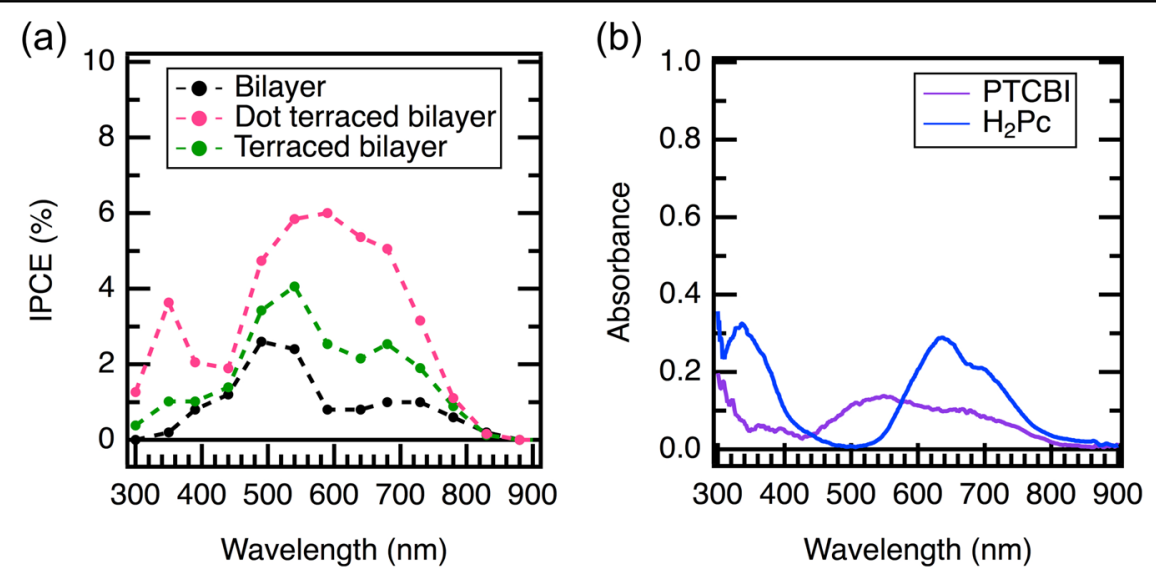

Fig. 8 a Action spectrum at $0 \mathrm{~V}$ vs. Ag/AgCl for the typical bilayer $\mathrm{H}_{2} \mathrm{Pc} / \mathrm{PTCBI} / \mathrm{TOO}$ (black), dot terraced bilayer $\mathrm{H}_{2} \mathrm{Pc} / \mathrm{PTCB} / / \mathrm{ITO}$ (red) $(8 \times 8$ dot patterns of the $\mathrm{H}_{2} \mathrm{Pc}$ layer on the PTCBI layer, diameter of each $\mathrm{H}_{2} \mathrm{Pc}$ dot $=200 \mu \mathrm{m}$, pitch $=200 \mu \mathrm{m}$; area ratio for $\left.\mathrm{H}_{2} \mathrm{PC}: \mathrm{PTCBI}=20 \%: 80 \%\right)$, and terraced bilayer $\mathrm{H}_{2} \mathrm{PC} / \mathrm{PTCBI} / \mathrm{ITO}$ (green) $\left(\mathrm{H}_{2} \mathrm{PC}\right.$ dimension $=0.3 \mathrm{~cm} \times 0.058 \mathrm{~cm}$, area ratio for $\left.\mathrm{H}_{2} \mathrm{PC}: \mathrm{PTCBI}=20 \%: 80 \%\right)$. Effective electrode area $=0.3 \mathrm{~cm} \times 0.3 \mathrm{~cm}$. The thicknesses for the PTCBI and $\mathrm{H}_{2} \mathrm{Pc}$ were $50 \mathrm{~nm}$ and $150 \mathrm{~nm}$, respectively. Light source wavelength: 300-900 nm, photon flux $=10^{16} \mathrm{~cm}^{-1} \mathrm{~s}$. Electrolyte: $\mathrm{KOH}\left(\mathrm{pH}\right.$ 11) +10 mM 2-mercaptoethanol. Light irradiation was from the $\mathrm{H}_{2} \mathrm{Pc}$ side. b Absorbance spectrum for PTCBI (50 nm) and $\mathrm{H}_{2} \mathrm{PC}$ $(50 \mathrm{~nm})$

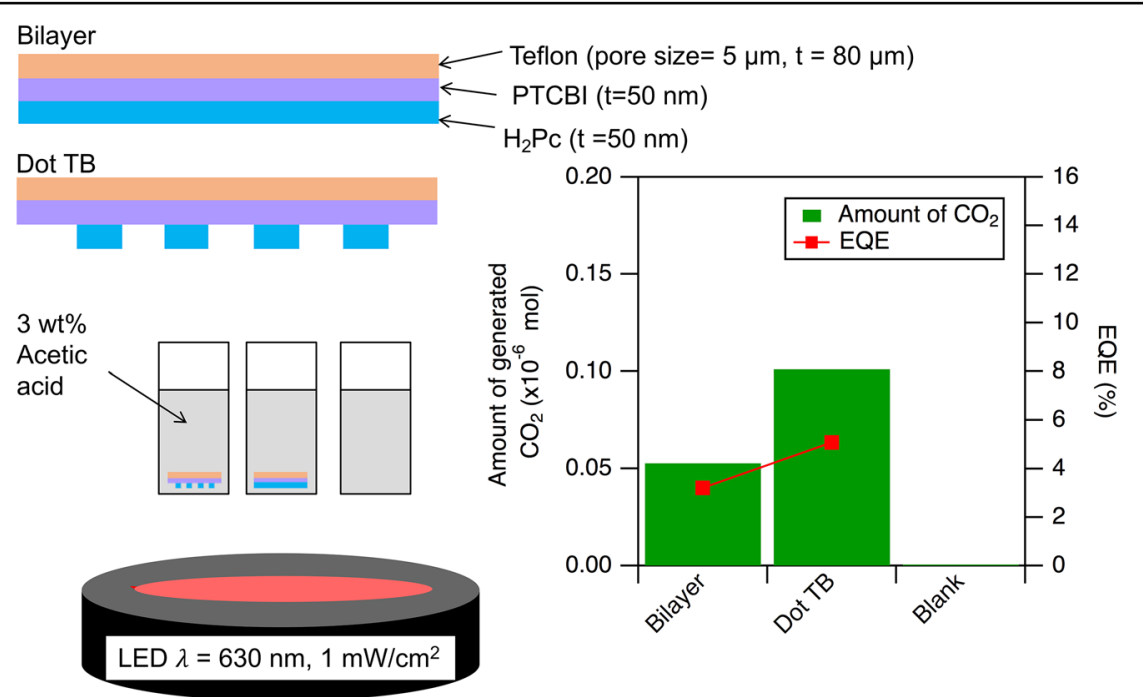

Fig. 9 Scheme for the experimental setup of the bilayer and dot terrace bilayer film photocatalyst to decompose 3 wt\% aqueous solution of acetic acid into $\mathrm{CO}_{2}$ under monochromatic light irradiation $\left(\boldsymbol{\lambda}=\mathbf{6 3 0} \mathbf{n m}\right.$, intensity $\left.=\mathbf{1} \mathbf{m W} / \mathbf{c m}^{2}\right)$. The dot terraced bilayer $\mathrm{H}_{2} \mathrm{PC} / \mathrm{PTCB} / \mathrm{s}$ Teflon membrane was prepared with a diameter of each $\mathrm{H}_{2} \mathrm{Pc}$ dot $=200 \mu \mathrm{m}$, pitch $=200 \mu \mathrm{m}$. Membrane size $\approx 0.6 \mathrm{~cm} \times 0.6 \mathrm{~cm}$. The thickness of both the PTCBI and $\mathrm{H}_{2} \mathrm{PC}$ was $50 \mathrm{~nm}$. The control sample was a container without any film that was kept under the dark condition. Light irradiation was from the $\mathrm{H}_{2} \mathrm{PC}$ side. The irradiation time was $1 \mathrm{~h}$. The result from the gas chromatography analysis is shown for the amount of $\mathrm{CO}_{2}$ evolution (in $\mathrm{mol}$ ) and $\mathrm{EQE}$ (in \%). The amount of $\mathrm{CO}_{2}$ in the blank sample was $0.02 \mu \mathrm{mol}$, and the value was zeroed to be the baseline value for the bilayer and the dot TB samples

the simple terrace sample were between those of the above two electrodes in terms of the EQE and spectral shape. The spectrum shape of the bilayer with a filter effect through $\mathrm{H}_{2} \mathrm{Pc}$ due to considerable quenching of the exciton of $\mathrm{H}_{2} \mathrm{Pc}$ was previously investigated ${ }^{40}$. For the present shape, the relatively higher EQE for $\sim 600 \mathrm{~nm}$ is due to less of a filtering effect due to the lack of full coverage by the $\mathrm{H}_{2} \mathrm{Pc}$ layer. This phenomenon also has the merit of enhancing the photoanodic current in addition to the effect on the BDR positive $V_{\mathrm{CPD}}$ peak.

To test the effect of the more positive potential in the BDR for an application, we fabricated $\mathrm{H}_{2} \mathrm{Pc}(50 \mathrm{~nm}) /$ PTCBI $(50 \mathrm{~nm})$ on a PTFE membrane filter $(80 \mu \mathrm{m})$ as the bilayer and dot terrace bilayer (Fig. 9) to investigate the photocatalytic performance in decomposing acetic acid under visible light irradiation $(\lambda=630 \mathrm{~nm}$, intensity $=1$ 
$\left.\mathrm{mW} / \mathrm{cm}^{2}\right)$. The control sample was a container without any film (i.e., a blank sample) that was kept under the dark condition. From the gas chromatography analysis, the dot terrace bilayer photocatalyst exhibited a higher performance than did the bilayer photocatalyst for the decomposition of acetic acid into $\mathrm{CO}_{2}$ gas. By assuming the following chemical equation:

$$
\mathrm{CH}_{3} \mathrm{COOH}+2 \mathrm{H}_{2} \mathrm{O}+8 h^{+} \rightarrow 2 \mathrm{CO}_{2}+8 \mathrm{H}^{+}
$$

the quantum efficiency, EQE (\%) (as in Eq. (1) and using $n=4$ ) was estimated to be $5.1 \%$ for the dot terrace bilayer sample and $3.2 \%$ for the bilayer sample. This result demonstrates that a more positive potential at the BDR can enhance the photocatalytic performance by enhancing the oxidation power.

\section{Conclusions}

This paper described the lateral $V_{\mathrm{CPD}}$ characteristic at the BDR for the terrace bilayer electrode of $n$-type PTCBI and $p$-type $\mathrm{H}_{2} \mathrm{Pc}$ and a comparison of the SLR and BLR. The analysis of the $V_{\mathrm{CPD}}$ values of the SLRs and BLRs was consistent with the electron transfer and vacuum level shift at the interfaces through the Fermi level alignment that occurs from the OSM into the ITO. For the BLRs, a $0.2-\mathrm{V}$ shift of $V_{\mathrm{CPD}}$ in the $50 \mathrm{~nm}$ top layer was observed, and the thickness-dependent $V_{\mathrm{CPD}}$ gave a more complicated energy level shift at the $p-n$ junction and band bending. For the BDR, there was a positive peak of $V_{\mathrm{CPD}}$ $\left(+0.1 \mathrm{mV}\right.$ for the BLR) for TB- $\mathrm{H}_{2} \mathrm{Pc} / \mathrm{PTCBI} / \mathrm{ITO}$, while for TB-PTCBI $/ \mathrm{H}_{2} \mathrm{Pc} / \mathrm{ITO}$, there was a broad and small peak of $V_{\mathrm{CPD}}$. The $V_{\mathrm{CPD}}$ peak is not an artifact, and the real value should be more than adequately observed due to the experimental resolution limitation. The $V_{\mathrm{CPD}}$ peak was impossible to interpret from the thickness-dependent $V_{\mathrm{CPD}}$ values. We may interpret it as a lateral direction charge separation. An enhanced oxidation power was confirmed by the use of a dot terrace electrode through photoelectrochemical observations at a smaller bias and with a lower filter effect from the $\mathrm{H}_{2} \mathrm{Pc}$ absorption. Moreover, the more positive potential at the BDR led to a high performance in the photocatalyst film for the decomposition of organic compounds. The enhancement of the oxidation power was experimentally proven to be a new design for a universal additional $p-n$ junction-type photocatalyst without changing the molecular component.

\section{Data availability}

All data are available from the corresponding author upon reasonable request.

\section{Acknowledgements}

We thank the Grant-in-Aid for Scientific Research (KAKENHI) and Five-Star Alliance for financial support, the Suzukakedai Analysis Support Center for the experimental facilities and Riken Keiki Co., Ltd. (especially Dr. S. Fujiwara, Dr. Y. Nakajima and Dr. T. Ishiji) for the photoemission yield spectroscopy in air (PYSA) facilities. We also would like to thank Prof. C. S. A. Musgrave and Prof. T. lyoda for assistance in preparing the manuscript and Mrs. Y. Oguchi for her assistance with the AFM measurements.

\section{Author details \\ 'Laboratory for Chemistry and Life Science, Institute of Innovative Research, Tokyo Institute of Technology, R1-26, Nagatsuta 4259, Midori-ku, Yokohama 226-8503, Japan. ${ }^{2}$ School of Microelectronic Engineering, Kampus Pauh, Universiti Malaysia Perlis, Arau 02600, Malaysia. ${ }^{3}$ Department of Frontier Materials Chemistry, Graduate School of Science and Technology, Hirosaki University, 3 Bunkyo-cho, Hirosaki 036-8561, Japan}

\section{Author contributions}

M.F.A. performed most of the experiments. M.S. and M.F.A. performed SKPM. K. N. supervised this project. M.F.A., T.A. and K.N. wrote the manuscript.

\section{Conflict of interest}

The authors declare that they have no conflict of interest.

\section{Publisher's note}

Springer Nature remains neutral with regard to jurisdictional claims in published maps and institutional affiliations.

Supplementary information is available for this paper at https://doi.org/ 10.1038/s41427-018-0058-x.

Received: 11 December 2017 Revised: 2 May 2018 Accepted: 24 May 2018. Published online: 17 July 2018

\section{References}

1. Tang, C. W. Two-layer organic photovoltaic cell. Appl. Phys. Lett. 48, 183-185 (1986).

2. Cui, Y. et al. Fine-tuned photoactive and interconnection layers for achieving over $13 \%$ efficiency in a fullerene-free tandem organic solar cell. J. Am. Chem. Soc. 139, 7302-7309 (2017).

3. Bin, H. et al. 9.73\% efficiency nonfullerene all organic small molecule solar cells with absorption-complementary donor and acceptor. J. Am. Chem. Soc. 139, 5085-5094 (2017)

4. Chen, S. et al. A wide-bandgap donor polymer for highly efficient nonfullerene organic solar cells with a small voltage loss. J. Am. Chem. Soc. 139, 6298-6301 (2017).

5. Kan, B. et al. Small-molecule acceptor based on the heptacyclic benzodi (cyclopentadithiophene) unit for highly efficient nonfullerene organic solar cells. J. Am. Chem. Soc. 139, 4929-4934 (2017).

6. Yang, L. et al. New wide band gap donor for efficient fullerene-free all-smallmolecule organic solar cells. J. Am. Chem. Soc. 139, 1958-1966 (2017).

7. Zhang, G. et al. High-performance ternary organic solar cell enabled by a thick active layer containing a liquid crystalline small molecule donor. J. Am. Chem. Soc. 139, 2387-2395 (2017).

8. Zhao, W. et al. Molecular optimization enables over $13 \%$ efficiency in organic solar cells. J. Am. Chem. Soc. 139, $7148-7151$ (2017)

9. Huang, Y., Kramer, E. J., Heeger, A. J. \& Bazan, G. C. Bulk heterojunction solar cells: morphology and performance relationships. Chem. Rev. 114, 7006-7043 (2014).

10. Peumans, P., Uchida, S. \& Forrest, S. R. Efficient bulk heterojunction photovoltaic cells using small-molecular-weight organic thin films. Nature $\mathbf{4 2 5}$ 158-162 (2003).

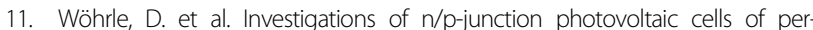
ylenetetracarboxylic acid diimides and phthalocyanines. J. Mater. Chem. 5, 1819-1829 (1995).

12. Morikawa, T., Adachi, C., Testuo, T. \& Saito, S. Multilayer-type organic solar cells using phthalocyanines and perylene derivatives. Nippon Kagaku Kaishi 1990 962-967 (1990). 
13. Yanagida, S., Kabumoto, A., Mizumoto, K., Pac, C. \& Yoshino, K. Poly(P-phenylene)-catalysed photoreduction of water to hydrogen. J. Chem. Soc., Chem. Comm., 474-475 (1985).

14. Nagai, K. et al. A full-spectrum visible-light-responsive organophotocatalyst film for removal of trimethylamine. ChemsusChem 4, 727-730 (2011).

15. Nagai, K., Yasuda, Y., lyoda, T. \& Abe, T. Multilayerization of organophotocatalyst films that efficiently utilize natural sunlight in a one-pass-flow water purification system. ACS Sustain. Chem. Eng. 1, 1033-1039 (2013).

16. Zhang, S., Sakai, R., Abe, T., lyoda, T. \& Nagai, K. Photoelectrochemical and photocatalytic properties of biphasic organic p-and $n$-type semiconductor nanoparticles fabricated by a reprecipitationProcess. ACS Appl. Mater. Interfaces 3, 1902-1909 (2011)

17. Zhang, S., Arunachalam, P., Abe, T., lyoda, T. \& Nagai, K. Photocatalytic decomposition of N-methyl-2-pyrrolidone, aldehydes, and thiol by biphase and $\mathrm{p} / \mathrm{h}$ junction-like organic semiconductor composite nanoparticles responsive to nearly full spectrum of visible light. J. Photochem. Photobiol. A 244, 18-23 (2012).

18. Arunachalam, P. et al. Weak visible light $\left(\sim \mathrm{mW} / \mathrm{cm}^{2}\right)$ organophotocatalysis for mineralization of amine, thiol and aldehyde by biphasic cobalt phthalocyanine/fullerene nanocomposites prepared by wet process. Appl. Catal. B: Environ. 193, 240-247 (2016)

19. Okemoto, A. et al. Application of picene thin-film semiconductor as a photocatalyst for photocatalytic hydrogen formation from water. Appl. Catal. B: Environ. 192, 88-92 (2016)

20. Coffey, D. C., Reid, O. G., Rodovsky, D. B., Bartholomew, G. P. \& Ginger, D. S. Mapping local photocurrents in polymer/fullerene solar cells with photoconductive atomic force microscopy. Nano Lett. 7, 738-744 (2007).

21. Chiesa, M., Bürgi, L., Kim, J. S., Shikler, R. \& Friend, R. H. Correlation between surface photovoltage and blend morphology in polyfluorene-based photodiodes. Nano Lett. 5, 559-563 (2005).

22. Palermo, $\vee$. et al. The relationship between nanoscale architecture and function in photovoltaic multichromophoric arrays as visualized by kelvin probe force microscopy. J. Am. Chem. Soc. 130, 14605-14614 (2008).

23. Liscio, A., Palermo, V. \& Samorì, P. Nanoscale quantitative measurement of the potential of charged nanostructures by electrostatic and kelvin probe force microscopy: unraveling electronic processes in complex materials. Acc. Chem. Res. 43, 541-550 (2010).

24. Liscio, A. et al. Photovoltaic charge generation visualized at the nanoscale: a proof of principle. J. Am. Chem. Soc. 130, 780-781 (2008).

25. Lyons, B. P., Clarke, N. \& Groves, C. The relative importance of domain size, domain purity and domain interfaces to the performance of bulkheterojunction organic photovoltaics. Energy \& Environ. Sci. 5, 7657-7663 (2012).

26. Fuchs, F., Caffy, F., Demadrille, R., Mélin, T. \& Grévin, B. High-resolution kelvin probe force microscopy imaging of interface dipoles and photogenerated charges in organic donor-acceptor photovoltaic blends. ACS Nano 10 739-746 (2016).

27. Hoppe, H. et al. Kelvin probe force microscopy study on conjugated polymer/ fullerene bulk heterojunction organic solar cells. Nano Lett. 5, 269-274 (2005).

28. Watanabe, S. et al. In situ KPFM imaging of local photovoltaic characteristics of structured organic photovoltaic devices. ACS Appl. Mater. Interfaces 6, 1481-1487 (2014).

29. Rojas, G. A., Wu, Y., Haugstad, G. \& Frisbie, C. D. Measuring the thickness and potential profiles of the space-charge layer at organic/organic interfaces under illumination and in the dark by scanning kelvin probe microscopy. ACS Appl. Mater. Interfaces 8, 5772-5776 (2016).

30. Saive, R., Mueller, C., Schinke, J. \& Lovrincic, R. Understanding S-shaped currentvoltage characteristics of organic solar cells: Direct measurement of potential distributions by scanning Kelvin probe. Appl. Phys. Lett. 103, 243303 (2013).

31. Ellison, D. J., Kim, J. Y., Stevens, D. M. \& Frisbie, C. D. Determination of QuasiFermi levels across illuminated organic donor/acceptor heterojunctions by kelvin probe force microscopy. J. Am. Chem. Soc. 133, 13802-13805 (2011).

32. Ishii, H., Sugiyama, K., Ito, E. \& Seki, K. Energy level alignment and interfacial electronic structures at organic/metal and organic/organic interfaces. Adv. Mater. 11, 605-625 (1999).

33. Tada, A., Geng, Y., Wei, Q., Hashimoto, K. \& Tajima, K. Tailoring organic heterojunction interfaces in bilayer polymer photovoltaic devices. Nat. Mater. 10, 450-455 (2011).

34. Harima, Y., Yamashita, K., Ishii, H. \& Seki, K. Energy structures of molecular semiconductors contacting metals under air studied by the diffusion potential measurements and the Kelvin probe technique. Thin Solid Films 366, 237-248 (2000).

35. Yang, C., Pyekh, Y. \& Danyluk, S. Surface potential imaging of PV cells with a Kelvin probe. Sol. Energy Mater. Sol. Cells 102, 167-172 (2012).

36. Satoh, N., Katori, S., Kobayashi, K., Matsushige, K. \& Yamada, H. Surface potential measurement of organic multi-layered films on electrodes by kelvin probe force microscopy. IEICE Trans. Electron. E98.C, 91-97 (2015).

37. Itoh, E., Nakamichi, H. \& Miyairi, K. Surface potential measurement of organic photo-diode consisting of fullerene/copper phthalocyanine double layered device. Thin Solid Films 516, 2562-2567 (2008).

38. Ishii, $\mathrm{H}$. et al. Energy level alignment at fullerene/phthalocyanine interface studied by electron spectroscopies. Mater. Res. Soc. Symp. Proc. 771, 29-34 (2003).

39. Mizuno, H., Nagano, K., Tomita, S., Yanagi, H. \& Hiromitsu, I. Organic photovoltaic cells with onion-like carbon thin films as hole collection layers. Thin Solid Films 654, 69-76 (2018).

40. Abe, T. et al. A novel and efficient system of a visible-light-responsive organic photoelectrocatalyst working in a water phase. ChemPhysChem 5, 716-720 (2004).

41. Abe, T. et al. An organic photoelectrode working in the water phase: visiblelight-induced dioxygen evolution by a perylene derivative/cobalt phthalocyanine bilayer. Angew. Chem. Int. Ed. 45, 2778-2781 (2006).

42. Abe, $\mathrm{T}$. et al. Wide visible light-induced dioxygen evolution at an organic photoanode coated with a noble metal oxide catalyst. J. Electroanal. Chem 587, 127-132 (2006).

43. Abe, T., Miyakushi, S., Nagai, K. \& Norimatsu, T. Study of the factors affecting the photoelectrode characteristics of a perylene/phthalocyanine bilayer working in the water phase. Phys. Chem. Chem. Phys. 10, 1562-1568 (2008).

44. Abe, T., Okumura, M., Kikuchi, Y., Itoh, T. \& Nagai, K. A dual-functional organic $\mathrm{p}-\mathrm{n}$ bilayer catalyst comprising a perylene derivative and cobalt phthalocyanine working under illumination and in the dark. J. Mater. Chem. A 5, 7445-7450 (2017)

45. Maki, T. \& Hashimoto, H. Vat dyes of acenaphthene series. IV. Condensation of perylenetetracarboxylic acid anhydride with o-phenylenediamine. Bull. Chem. Soc. Jpn. 25, 411-413 (1952).

46. Nagai, K. et al. Drastic photoluminescence quenching of perylene derivative membrane with phthalocyanine coating. Chem. Lett. 30, 354-355 (2001).

47. Sadewasser, S. \& Glatzel, T. Kelvin Probe Force Microscopy. 48, (Springer Science \& Business Media, 2011). pp. 14.

48. Yamashita, D. \& Ishizaki, A. In situ measurements of change in work function of $\mathrm{Pt}, \mathrm{Pd}$ and Au surfaces during desorption of oxygen by using photoemission yield spectrometer in air. Appl. Surf. Sci. 363, 240-244 (2016).

49. Yan, F., Chen, G., Lu, L. \& Spanier, J. E. Dynamics of photogenerated surface charge on $\mathrm{BiFeO}_{3}$ films. ACS Nano 6, 2353-2360 (2012).

50. Schlaf, R., Murata, H. \& Kafafi, Z. H. Work function measurements on indium tin oxide films. J. Electro Spectr. Relat. Phenom. 120, 149-154 (2001).

51. Yamashita, D., Ishizaki, A. \& Yamamoto, T. In situ measurements of work function of indium tin oxide after UV/Ozone treatment. Mater. Trans. 56, 1445-1447 (2015)

52. Kim, G. Y. et al. Work function change on O-plasma treated indium-tin-oxide. J. Mater. Sci. Engineer.: B 100, 275-279 (2003).

53. Kim, J. S. et al. Kelvin probe and ultraviolet photoemission measurements of indium tin oxide work function: a comparison. Synth. Met. 111-112, 311-314 (2000).

54. Sadewasser, S., Leendertz, C., Streicher, F. \& Lux-Steiner, M. C. The influence of surface topography on Kelvin probe force microscopy. Nanotechnology $\mathbf{2 0}$ 505503-11 (2009).

55. Gorgoi, M. \& Zahn, D. R. T. Charge-transfer at silver/phthalocyanines interfaces. Appl. Surf. Sci. 252, 5453-5456 (2006).

56. Hill, I. G., Schwartz, J. \& Kahn, A. Metal-dependent charge transfer and chemical interaction at interfaces between 3,4,9,10-perylenetetracarboxylic bisimidazole and gold, silver and magnesium. Org. Electron. 1, 5-13 (2000).

57. Yogev, S., Matsubara, R., Nakamura, M. \& Rosenwaks, Y. Local charge accumulation and trapping in grain boundaries of pentacene thin film transistors. Org. Electron. 11, 1729-1735 (2010).

58. Pertram, T., Moors, M. \& Wandelt, K. Phthalocyanine adsorption on Au(110): 1D ordering and adaptive reconstruction. J. Phys.: Condens. Matter 28, 434001 (2016). 